\title{
Using Innovative Web Tools to Empower Language Learners
}

\author{
John Paul Loucky, Ed. D. \\ Seinan JoGakuin University Professor, \\ Kitakyushu, JAPAN \\ Homepage: www.CALL4ALL.US; \\ Email: loucky@seinan-jo.ac.jp
}

Abstract - Whether in ELI or TESOL programs in Englishspeaking countries, or in their home countries, English language learners (ELLs) have special needs for programs that can help them to overcome low levels of $\mathrm{L} 2$ vocabulary and other barriers to their success. Though technology has great potential to help language learners better understand and use word meanings, the full potential of technology has not yet been fully explored or exploited. This article reviews studies and presentations by the author on ways to help maximize vocabulary and reading development online. Needs of limited English proficiency learners, especially those from East Asia are addressed, with many recommendations given of ESL/EFL Gold programs with greatest potential to help increase motivation and spur more rapid $L 2$ acquisition. The pedagogical goal was to find multi-level, integrated CALL programs that serve to increase language learners' (LLs) use of glossing programs and interactive programs so as to help them to rapidly build up their target language (TL) vocabulary and reading skills. The overall aim of this presentation is to rapidly review and recommend some of the finest online literacy tools and so-called "EFL Gold" Websites that can help to empower language learners. Two additional goals were 1) to share knowledge of new era trends and technologies for improving language learning; and 2) to visualize online tools we can use to improve language and computer literacy for any language by using a PowerPoint to compare various Glossing Engines for improving online reading and language learning technology. In this APTEL presentation 50-5,000 Websites and links were shown that can be used to improve both language and computer literacy. There we described a distance learning project between Chinese and Japanese students using an author-designed Semantic Field Keyword Approach (Loucky, 2004) for advanced English vocabulary learning for Chinese, Japanese and Arabic students.

Keywords-component; Web 2.0 Tools; E-Learning

\section{CATEGORIZING WeB 2.0 TOOLS}

My World CALL Directory (at www.CALL4ALL.US) is an Open Source research repository that integrates various glossing engines, widgets and Web 2.0 tools for about 150 languages. It helps teachers to focus on Building Language Learning Strategies, stressing the primary importance of vocabulary acquisition for balanced SLA.. Most people would agree that vocabulary learning is at the heart of mastering a foreign language. In the view of many students of second languages, and perhaps their teachers as well, developing a good vocabulary is the most important part of learning another language. In fact, knowing and using effective vocabulary learning strategies is now known to be essential for language learning success. Lexical competence is clearly an essential component of linguistic proficiency.

\section{E-LEARNING RESEARCH WITH ENGINEERING STUDENTS}

\section{Graduate Engineering Students in Japan}

The English classes where I have done much of my research on the use of computerized portable and online dictionaries have been at one of the best Engineering universities in Kyushu, JAPAN. Online programs reviewed in my former studies reflect current research and practice in second language vocabulary teaching and learning and demonstrate the need for a systematic approach to vocabulary instruction and the development of effective vocabulary acquisition skills when learning online as well as from traditional print materials. Crucial information needs to be provided to help teachers 
decide which words should be learned and for what purpose, and whether the emphasis should be on quantity or quality, implicit or explicit learning, and receptive or productive use. To be most effective, language teachers need to have a clear model of vocabulary acquisition in their minds and use online programs that help their learners come to a fuller productive knowledge of words. In addition, various teaching techniques need to be used, along with both useful print and online resources to help L2 readers develop their own repertories of vocabularybuilding strategies and activities.

One of our goals today and at earlier IT conferences in Hainan last year and in Xian before that was to illustrate how to design a $21^{\text {st }}$ Century Curriculum Using Web 2.0 Tools. We also studied various portable and online dictionaries and "Glossing Engines" to help improve online language learning, especially in Asia. In various sessions of this year's conference we will discuss "How to enhance online reading in a global age," and how to design CALL Programs to help motivate SLA and SLVA, as well as examine E-Reading Research questionsmeaning both E-books and electronic reading as well as Extensive Reading-- in need of more study.

\section{LITERATURE REVIEW:}

Whether it's a knife or gun powder, the fact that technology can cut both ways is known as its bivalent nature. Few may know how closely connected the development of atomic bombs and computers were. This story was spelled out by Dyson's (2012) Turing's Cathedral: The origins of the digital universe. There he shares how "computers and nuclear weaponry share a common genesis ... . each technology spurred the other's development" (p. 170). Similarly, since both human and mechanical abilities are limited, we should not expect too much of computers or AI. "Machines, in brief, cannot take us to a qualitatively better world, just a souped up version of the same world," as Grandy (2013) wisely concludes in his essay on "The Future of IT." In Divining a Digital Future: Mess and Mythology in Ubiquitous Computing by Paul Dourish and Genevieve Bell (2011) thoughtfully reflect on Ubiquitous computing (or ubicomp) which is the label for a "third wave" of seamless, Internet Everywhere computing technologies.

Going back to some major points from APTEL Conference, one major aim was to share so called "Golden Multi-level EFL and other language learning sites," which we challenge our engineering and E-Learning students to test, summarize and present to their peers. In order to empower their learning how, we are now adding many widgets and scrollable summaries to the top of each of our class site pages, which we will demonstrate shortly. This makes quick review and practical testing much easier for prospective teachers or engineers to do on their own for selfaccess study. Quoting a bit more from a previous APTEL, allow me to summarize Cofino's (2009) excellent summary on "Integrating $21^{\text {st }}$ Century Multi-Literacy Skills into Global Education." She wrote that

1) $21^{\mathrm{ST}}$ Century Literacy Skill training must be global and international in scope;

2) Ubiquitous/Always on everywhere;

3) Instantly Accessible for on-time delivery;

4) Blending/Integrating both old traditions and new ways empowered by modern technology;

5) Mobile/Portable;

6) Adaptable/Customizable: able to be individualized to match and maximize each learner's full needs and potential, as well as each region's local language, educational and commercial needs;

7) Flexible in terms of values and prices; and finally

8) Collaborative, not overly independent.

Likewise, various media forms have different affordances, i.e. they may provide a different level of support for various kinds learning experiences. The differences in learning experiences, methods and media forms used by various technologies have been helpfully charted by Peter Clinch (2005) as follows in Table 1: 
Table 1: Learning methods and media forms

\begin{tabular}{|c|c|c|}
\hline learning experience & method/technologies & media forms \\
\hline $\begin{array}{c}\text { attending, } \\
\text { apprehending }\end{array}$ & print, TV, video, DVD & narrative \\
\hline $\begin{array}{c}\text { investigating, } \\
\text { exploring }\end{array}$ & $\begin{array}{c}\text { library, CD, DVD, Web } \\
\text { resources }\end{array}$ & interactive \\
\hline discussing, debating & $\begin{array}{c}\text { seminar, online } \\
\text { conference }\end{array}$ & communicative \\
\hline $\begin{array}{c}\text { experimenting, } \\
\text { practising }\end{array}$ & $\begin{array}{c}\text { laboratory, field trip, } \\
\text { simulation }\end{array}$ & adaptive \\
\hline $\begin{array}{c}\text { articulating, } \\
\text { expressing }\end{array}$ & $\begin{array}{c}\text { essay, product, } \\
\text { animation, model }\end{array}$ & productive \\
\hline
\end{tabular}

\section{E-LEARNING R\&D PROJECTS}

The writer's graduate Engineering English students are asked to test and evaluate various sites regarding their helpfulness for learning more English and Engineering. Though at a simpler level, evaluation criteria used by Gi-Zen Liu, ZihHui Liu and Gwo-Jen Hwang (2011) were referred to, since they provide a practical application of E-Learning and Integrated English by asking each student to evaluate and test particular pages or programs from the English class website. Web-based learning can encourage cross-cultural communications and understanding to grow, as young learners also become more globally aware of a bigger world than their own cultural backyard. In Laurillard's (2002) view Elearning environments may be divided into these five major types:

1) Narrative (using linear presentation)

2) Interactive (both presentational and user-responsive media)

3) Adaptive Media (modeled first for user response)

4) Communicative (discussion-oriented media)

5) Productive (Student action-oriented media)

\section{INNOVATIVE TECHNOLOGIES USED TO EMPOWER ENGINEERING STUDENTS' ENGLISH}

IGI has highlighted many useful technologies in its digital library and journals. The author contributed to several of those, discussing how to enhance online reading and readability (in Loucky, 2010, 2011 and Loucky \& Tuzi, 2010). Each teacher also needs a PLN or Personal Learning Network to continue life-long learning online, as it is hard for anyone alone to keep up with the lightning speed of development in this complex field. Four which I recommend are Best links from Larry Ferlazzo, Tech Tips from David Kapuler, insights from George Siemens, and Mindmeister maps from Robin Good. Diigo.com learning community and annotation tools can also help greatly. But best of all tools which our fall classes will begin using for curating and sharing programs from within the class site and elsewhere online is Symbaloo.com, which will become our class site during hands on experimental research phase of the course.

Favorite and most effective sites used by the 2012 Engineering Integrated English class were IMTranslator.net, providing both glossing and listening (TTS) support, WordChamp.com and the class site with its many online dictionaries, reading labs and engineering articles. Technical challenge given and solved with students was how to make any print text online to add these language supports to any text. That problem was solved by using Fujitsu's portable Scan-Snap. Older classes had faced the challenge of adding glossing to any language online, solved by using WordChamp.com. The latest challenge has been pedagogical, how to enhance E-learning skills. Since most students were slow to do online curating, despite being graduate level engineering students, the author has designed a new site to be used from Fall 2013, Symbaloo.com, where he has pre-set menus and Webtools, so they should have no excuse. Two buttons added that will provide instant access to multiple tools are EdTech and EdShelf.com, to be demonstrated at conferences after quick PowerPoint overview of the course objectives. 
Such new E-learning technologies offer many advantages, including these summarized from Allford and Pachler (2007, Pp. 213-222): greater flexibility, multimodality, interactivity, non-linear, hyper-linked inter-connectivity, networking and collaboration tools, distributed non-centralized "Communities of Practice" noncentralized for searching and co-creation of information. Although we know this to be true and recognize that none of us can possibly keep track of all the burgeoning plethora of so many Elearning tools, far too few teachers are involved in daily, active PLN or personal learning networks, although many exist online. We all must learn more about these tools as our world faces so many basic changes in both what and how we learn.

\section{A. Curriculum 21 Insights}

Jacobs' article in Curriculum 21 can help us to better rethink what kind of curriculum is needed for $21^{\text {st }}$ Century literacies to be developed. New mindset is needed to shift us from several myths of traditional thinking and teaching. Teachers need to move: a) from knowing the right answers to knowing how to behave when answers are not readily available, b) from transmitting meaning to participating actively in discovering and constructing meaning, c) from external evaluation to self-assessment and self accessing of information (Accessible from

http://www.flickr.com/photos/langwitches/sets/72 157625820681647/show/).

\section{B. Five Current Socio-Technology Trends:}

Five Socio-Technology trends can be seen in much current e-learning that emphasize these aspects of learning:

1) "Learning to Do" or Social Production (cocreation of knowledge common to constructivist views) and learning by doing;

2) "Learning to Be" or Social Networking (emphasizing relating versus technologies);

3) "Learning to Know" or the Semantic Web (organizing, interpreting, connecting or distributing information);
4) "Learning to Be and Do" via Media Grids, where content is not just linear, gaming may be used; and

5) Non-Linear Learning, where all disciplines are interconnected. In this process of reenvisioning education, we can also see a healthy shift away from seeing the teacher as an information provider, to that of a facilitative coach, innovator, catalyst and collaborator with the learner. Likewise self-accessing of learning is stressed with learning goals and curriculum that are life-long. Finally, learners themselves learn to search for and assess data and their own learning progress, valuing feedback, and modifying their own learning journey.

\section{Appropriate Online LL Strategies Instruction}

Appropriate training in the use of most effective language learning strategies has been shown to be most helpful to language learners for these two reasons, stressed by Anderson (2005). Firstly, "Successful language learners have a wider repertoire of strategies and [can therefore] draw on a variety of them to accomplish their task of learning a language. (2005, p. 757). Secondly, “...metacognitive strategies play a more significant role because once a learner understands how to regulate his or her own learning through the use of strategies, language acquisition should proceed at a faster rate" (2005, p. 766). Finally, three areas still in most need and deserving of more careful research, especially to see how use of CALL/TELL or SMALL resources can best help to improve language learning and teaching are probably the same as those noted by Anderson (2005, p. 767) in his review of L2 learning strategies, although in reverse order:

1) the role of computers in L2 strategy research,

2) strategy use in L2 vs. L1 language learning contexts, and 3) how are language learning styles and strategies related?

\section{Pedagogical Implications and Future Research}

It is becoming increasingly clear that CALL, and especially SMALL solutions help to facilitate 
student autonomy and enhances language learning motivation. As Vance Stevens (2009) coined that term "SMALL" during the 25th anniversary of CALL-IS at the TESOL conference [\#8 of http://www.slideshare.net/vances/celebrating25-years-of-call), Social Media-Assisted Language Learning has become "all the rage" with the lightning speed spread of Internet and mobile devices.

More testing needs to be done of the author's integration of Grabe's (2004) ten principles from L2 reading research with CALL to maximize online vocabulary and reading comprehension. In a similar way 14 CALL principles collated by Hirschel (2012) were integrated with Chapelle \& Jamieson`s previous guidelines and Tips (2008) for better operationalizing CALL in the classroom. Both can help provide a practical framework with clear directions for future strategy research, which this study follows in its strategy instruction approach with Engineering students.

\section{VLS Strategy Instruction, Practice and Assessment}

This research built upon previous studies (Loucky, 2005, 2006, 2010) of Vocabulary Learning Strategies (or VLSs) known versus used by Japanese college students of English. The classes being compared were both graduate Engineering students of Integrated English, an online reading/writing course designed by the writer. It's syllabus and sample online readings may all be viewed on $G$ page of the class website, www.CALL4ALL.us.

\section{Population: included 45 graduate Engineering} students, 3 of whom were Chinese and 3 of whom were females. To better compare their vocabulary learning strategies from year to year a Vocabulary Learning Strategies (VLS) Survey was given over several years. About 50 VLS were listed under two sections, to better ascertain and train students in strategy instruction and use. Section I covered "Techniques used for learning the meaning of new words, or Initial Learning Strategies." Section II surveyed their use of Consolidation Strategies, or techniques for studying and remembering new words." Although the survey itself is too long to include, its results will be summarized to show VLS preferred and listed as most helpful in each of these areas of learning.

\section{Survey Results}

Hopefully any reading teacher can model effective reading habits and strategies, both in print and online and not only when using graded readers. However, a more fair comparison would be for us to be able to model our own L2 reading practices, that is, what do we do regularly to improve our reading of Japanese or another host culture L2 to reach more near-native level? As usual, "talk is cheap" but the proof of real pedagogical effectiveness is shown by our own daily practices. (Who's reading at a near-native level in a FL, and if so how did you get there? Do you still do so daily?)

\section{Comparing Initial Learning versus Consolidating Strategies:}

\section{SECTION I: Initial Learning VLSs:}

1st 29 or $64 \%$ listed VLS H "Use a bilingual dictionary" as the most helpful "Initial Learning Strategy."

2nd 26 or $58 \%$ listed their most frequent VLS was M. "Guess meaning from context" Most used, valuable VLS.

3rd most used VLS by $44 \%$ or 20 students was J. "Check part of speech (POS)."

4th 17 or $38 \%$ used A "Pictures or gestures to understand meanings." An equal number or

4th 17 or $38 \%$ also said G. "Use an English dictionary." Combined with those using Bilingual Dictionaries (VLS H) ALL students claimed to be using some dictionary VLS.

5 th 13 or $29 \%$ said C. They ask their classmates. 6th 10 or $22 \%$ wrote I. "Check prefixes, suffixes and root words to discover meaning."

7 th 8 or $18 \%$ said $\mathrm{K}$, they "Think about related words," yet Japanese has few English cognates. 8th, 7 or $15.5 \%$ wrote E, "Ask teacher for Japanese translation," (teachers discourage this). 


\section{SECTION II: Consolidating Learning VLSs: (back side of survey)}

1st -29 or $64 \%$ said H. "Take notes in class about new words."

2nd - 26 said M, "Connect new word to some situation in your mind (i.e. "Associate them!)"

3rd - 20 wrote J, "Use Phonetic sounds to remember new words."

4th- 17 stated A. "Paraphrase meaning of new words." TIED with

4th -17 also said the G, "Use physical action when studying words."

5th- 13 C. "Use "Scales to study certain adjectives."

6th - 11 use I, "Study words with a group of students." Few are seen doing so together in class. 7th - 10 use L, "Study spelling of a word." Lastly, 8th 7 students use E. "Word Lists to study new words," a habit taught by most schools.

\section{Independent VLSs to Encourage Online SLVA}

In repeated surveys over the past decade most Japanese students surveyed have not reported using many effective strategies for organizing or improving their vocabulary learning. Rather, they seem to employ the same old East Asian method commonly used for learning L1 characters, simply repeatedly writing and trying to remember them much as they would new script in their mother tongue. However such rote memorization is normally not very effective since it is mostly done out of context. As the author advised in 2005,

Their learning would be greatly improved if language teachers could help learners to use the benefits of portable and online dictionaries to better organize new words into related groups by common themes, domains or keywords (Coll, 2002). The Semantic Field Keywords Approach (Loucky, 2004) has been used successfully to do this with about 2,000 advanced vocabulary words now available at: <www.call4all.us///misc/sfka.php).
The automatic archiving and reviewing ability provided by most electronic dictionaries' Search function is recognized by skillful users as being one of its major strengths and advantages over print lexicons. This is because they can remember new words students look up, even auto-archiving them in History Searches or Memos, allowing them to review and activate new words later with greater ease than ever before. Summariz-ing this advantage, "Auto-archiving and review functions help to reduce an otherwise overly heavy cognitive load on learners' L2 mental lexicons and memory retention ability. .. [However] Training is needed. . . in the effective use of both portable and online dictionaries. . . students need to be shown how to copy and paste new word definitions and examples into their own Vocabulary Notebooks in Word, or other archive files for practice and review."

(Loucky, 2005, p. 19).

Depth of Lexical Processing Scale

Since 2002-2003 this writer has presented and tested a 10-part Depth of Lexical Processing Scale, which serves as a pedagogical framework for teaching major lexical processing steps, skills and strategies to foreign language learners. Its 10phase system can help to guide and simplify vocabulary instruction including these steps (as shown in Table 1. This "Model of Reading Comprehension and Vocabulary Processing" and the following chart comparing the emphases of IR and ER first appeared in Loucky, (2005). The author's "Taxonomy of VLS or Depth of Lexical Processing Scale (DLP Scale) includes:

Part I: Discovering VLSs

1. Assessing-Ask "How well do I know these words?" \& Fill in DAVIE VKS

2. Accessing-Do I quickly find clues as to their Meanings? 
3. Analyzing -Do I know how to "Divide \& Conquer words into their meaningful parts?"

4. Archiving-Do I consistently record new words where I can find them again (in print/online?)

5. Anchoring - Do I anchor new word meanings using memorable Hint/Clue/Links?

Part II: Consolidating VLSs

6. Associate /Organize-Do I have a system where I organize new word meanings?

7. Activate-Do I Activate by USING new words in writing/speech ASAP/AMAP?

8. Anticipate-Do I predict words in appropriate contexts, either in L2 (Controlled vs. Free Production) via Exercises in: a) Reading Cloze, b) Listening Cloze Exercises, or c) with Correct Collocational or Social Use/ Register.

9. Re-Assess/Post-test. Do I re-check wordlearning by post-testing any TL VLS or vocabulary?

10. Recycle/Review-Do I Review \& Recycle any missed words and Plan New Encounters?

Plan ways to Re-meet, Re-Encounter and ReLearn any missed words, i.e. Repeat the learning cycle once again in new contexts often, to extend and reinforce their meanings and strengthen long-term (LT) retention? Do I repeat this "Deeper Lexical Processing" (DLP) learning cycle until target words become assimilated/internalized and retained, which is shown once they are automatically recognized or produced?

\section{Comparison of VLS Studies}

In repeated surveys about whether and which VLSs Japanese students use, the author has found that most show a low average use of such strategies for learning new words, except for a minority of students in most advanced classes studied (Graduate Engineering students). In his 2006 study this writer found 3 general approaches to vocabulary learning among East Asian learners tested-ranging from 1) Random, unstructured types who used less than 3 DLP steps, randomly and inconsistently; to 2) Semi-structured, meaning those who use 4-5 DLP steps consistently; to 3) Systematic, structured types, who use 6-8 or more DLP consistently to learn new words. (For details see Loucky, 2006,

Table 6).

Critical Ongoing Studies by Katagiri

Katagiri (2012) noted that contrary to normal patterns of regular increase the longer one studies, in his studies of Japanese college students of English the variations (i.e. SDs) of vocabulary size became smaller as they took more English classes or studied English longer. He regularly used Mochizuki's (1998) VST to test levels of both high school and college students over each year of study. Katagiri's most recent study (2012) used longitudinal measures of receptive vocabulary size of Japanese English major students in various years of their university study.

In summary, he found that the most frequent of vocabulary development patterns found--shown for $31.2 \%$ of them--was a flat plateau type in their freshman year, followed by an increase in their second year. Though he was surprised that even English majors did not improve or increase their vocabulary size as freshmen, this finding was echoed earlier by Yamamoto (1990) at the author's Japanese college as well. In fact, even engineering students did not show any sizable growth in their English vocabulary between freshman and graduate years, a full four years later, when their 1996 and 2000 
scores were compared (Loucky, 1996 and 2006). This means that only $22 \%$ or about $1 / 5^{\text {th }}$ of all his participants steadily increased their English vocabulary each year, a sobering assessment for teachers in Japan.

A majority of Japanese students, even at a graduate level who were tested seemed to lack some of the most basic effective vocabulary learning habits, and many college freshmen, even English majors often do not improve their vocabulary during their entire first year of study (See Katagiri 2012 report). This seems to be because most have not had effective training in how to use a wider variety of effective VLSs systematically, and thus they use relatively few when trying to learn new TL terms. As noted by the writer previously, "It appears that secondary Japanese education in many cases has failed to provide students with the necessary core vocabulary to become more independent language learners and fluent readers in English. Neither has it adequately trained many of its high school and college students by giving them a systematic and effective approach to learning how to both remember and use new TL forms and meanings. As a result, their progress in learning any foreign language in general has been severely hampered." (Loucky, CALICO 2006, pp. 381-382)

It is high time for teachers, governments and materials writers to give foreign language learners a systematic online approach that works to help them learn most frequent, common core vocabulary using an online system that enables them to discover and consolidate the meanings, forms and usage of new words using these ten crucial steps, since deeper processing promotes better learning and retention.
Procedure

Students can do Free/Extensive Reading using this and many similar online Reading Labs. To help maximize their comprehension, enjoyment and effectiveness of online reading texts and activities, it is greatly to the teacher's and learners' advantage to be able to add such features as Text-to-Speech for Listening support (often called Extensive Reading and Listening); Instant Glossing (Using WordChamp or Rikai.com, etc); and Vocabulary Auto-Archiving features which both of these have, for later review at their own leisurely pace without distracting them from reading enjoyment. An example of a good Online Reading Lab with ER+ auto-corrected comprehension questions and a pacer is Balsamo's, found at http://webspace.webring.com/people/bc/call4allus /readinglab.htm .

\section{Recommendations}

ESL/EFL teachers should help learners focus on and practice beneficial strategies for improving their TL vocabulary, reading skills, and reading fluency. Many aspects of both IR and ER might be better facilitated by CAI/CALL and Webbased methods and materials, if teachers and software/website designers would seek to more effectively combine the benefits of both Intensive and Extensive Reading types, techniques, and strategies to help online readers improve their L2 comprehension and vocabulary development whenever reading online, whether for information, enjoyment, or both (as outlined in Tables 1 \& 2)

Based on general findings by various reading researchers, Grabe (1991) developed some useful guidelines for reading programs, which need modifications for ideal use in second or foreign language situations, especially when computer assisted language learning is being used (Grabe, 2000).

\section{Most Highly Recommended Vocabulary} Learning Programs:

The following vocabulary learning methods and programs have been found to be among the most effective when used by this writer with 
intermediate and advanced Japanese English learners. Among recommended programs tested, these were deemed most helpful:

1. Semantic Field Keyword Approach (27 Quizzes, Retrieved with Chinese from

http://www.call4all.us///misc/sfka.php)

2.. Vocabulary Assessment Forms-Author-

designed for free classroom use, accessible

http://www.call4all.us///home/_all.php?fi=../misc/ forms). V-Page). ***On-line DAVIE VKS Form, VLS Taxonomy and Depth Scale.

3. Multi-level online reading labs and vocabulary programs listed on V-Page, i.e. programs recommended to enhance each lexical processing phase.

4. Integrated Multi-level programs like ESL Gold.net and WebMixer www.Symbaloo.com.

5. Data-Driven Learning, (DDL) or corpus-based language learning using authentic texts.

\section{VLS Activities and Monitoring Sheet:}

ELL/ESL/EFL/TESOL Teachers should aim to help language learners develop consistent computer-assisted habits of systematically organizing their processing of new words to best maximize their Target Language vocabulary development, by regularly including these steps:

1) Attending and Assessing, 2) Accessing,

3) Archiving, 4) Analyzing, 5) Anchoring,

6) Associating, 7) Activating, 8) Reviewing/ Recycling, 9) Reassessing, and 10) Relearning by Re-meeting or Repeated encounters with TL vocabulary, in many contexts with new syntactical forms. Use this Table to help you brainstorm for better VLS ACTIVITES and Online Programs:

CALL Efficacy Model-Qing \& Kelly (2009) provide best model of CAVL so far. Qing (2009) also presents one of the most thorough reviews of Second Language Vocabulary Acquisition (SLVA) and of VLSs also. To enhance the teaching of these areas and strategy instruction using CALLbased word learning, teachers and developers should aim to incorporate and follow these seven commonly accepted parameters:

\section{1) Good Learner Fit:}

Do the vocabulary words fit learners' needs and topics? Do they match learners' language levels?

2) Explicit vocabulary Teaching: Do activities provide Explicit Instruction to teach words?

3) Good CIA: Computer Interaction: Do Computer Interaction activities focus learners' attention on new words? Do computers help students to understand new words?

4) Good LIA: Learner Interaction:

Do activities guide learners to work with classmates and contribute to online discussions? Can you develop other Collaborative Learning Activities based on this target vocabulary?

5) Frequent and Immediate EV: Evaluation Feedback or Quizzes:

Do activities give Feedback to learners about their responses? Are Quizzes provided to help evaluate learning outcomes, giving learners immediate feedback and correction about their performance, to help motivate them?

6) Strategy Training Development ("Positive STDs"):

Do activities promote good vocabulary learning strategies (VLSs)? Do activities promote good reading comprehension strategies? Do activities provide guidance to learners about good online tools and strategies to keep learning new words using Internet and mobile applications? 


\section{7) Rate or Degree of Enhancement (Over Traditional Print):}

How do these digital tools and programs enhance word learning and reading online in ways preferable to print reading?

\section{REFERENCES}

[1] Allford, D., and Pachler, N. (2007). Language, Autonomy and the New Learning Environments. Bern: Peter Lang.

[2] Anderson, N. J. (1991). Individual differences in strategy use in second language reading and testing. Modern Language Journal, 75, 460-472.

[3] Anderson, N. J. (2005). L2 strategy research. In E. Hinkel (Eds.), Handbook of research in second language teaching and learning (pp. 757-772). Mahway, N.J.: Lawrence Erlbaum Associates. Retrieved http://dafl.ntpu.edu.tw/files/news/56_0bf0e1bf.pdf

[4] Anderson, N.J. (2003). Metacognition in writing: Facilitating writer awareness. In A. Stubbs \& J. Chapman (Eds.), Rhetoric, uncertainty, and the university as text: How students construct the academic experience (pp. 10-30). Canadian Plains Research Center, University of Regina: Regina, Canada.

[5] Chapelle, C. A., \& Jamieson, J. (2008) Tips for Teaching with CALL: Practical approaches to computer-assisted language learning, (Ed.) H. Douglas Brown. Pearson Education: N.Y.

[6] Clinch, P. (2005). Supporting law teaching: training and teaching, Presentation at UKCLE seminar on teaching and learning for legal skills trainers, 16 February 2005.

[7] Cofino, K. (2009). Online Presentation on Intercultural Learning \& Technology. Online at http://langwitches.org/blog/2011/04/01/third-culturekids/.
[8] Cohen, A. \& Macaro, E. (2007). Language Learner Strategies: 30 Years of Research and Practice. OUP Oxford.

[9] Dourish, P., \& Bell, G. (2011). Divining a Digital Future: Mess and Mythology in Ubiquitous Computing. The MIT Press, Cambridge, MA,

[10] Dyson, G.B. (2012). Turing's Cathedral: The origins of the digital universe. NY: Pantheon Books.

[11] EdShelf. https://edshelf.com/create-collection. Students learn how to create Widgets using: https://edshelf.com/widgets .

[12] EdTech. http://edtechtoolbox.blogspot.jp/p/web2-tools-by-task.html [Find Ed Tools you need!]

[13] Gi-Zen Liu, Zih-Hui Liu and Gwo-Jen Hwang (2011). Developing multi-dimensional evaluation criteria for English learning websites with university students and professors. Computers \& Education 56 (2011), 65-79.

[14] Grabe, W. ( 2004). Research on teaching reading. Annual Review of Applied Linguistics, 24, 44-69.

[15] Grandy (2013) "The Future of Information Technology." Review Essay in Journal of Interdisciplinary Studies, Vol 25, No. 1/2, pp. 161-176.

[16] Gu, Y., \& Johnson, R. K. (1996).Vocabulary learning strategies and language learning outcomes. Language Learning, 46, (4) 643-679.

[17] Hirschel, R. (2012). Moodle: Students perspectives on forums, glossaries and quizzes. JALT CALL Journal, Vol. 8, No. 2. p. 97, Table 1.

[Retrieved from http://journal.jaltcall.org/articles/8_2_Hirschel.pdf]

[18] Huang, Hsin-chou, Chiou-lan Chern, Chih-cheng, Lin. (2009). EFL learners' use of online reading strategies and comprehension of texts: An exploratory study Source. Computers \& Education, Volume 52 , Issue 1.

[portal.acm.org/citation.cfm?id=1464531.1465358]

[19] Jacobs, H. H., Ed. (2010). Curriculum 21Essential Education for a Changing World, ASCD. 
[20] Jamieson, J. \& Chapelle, C. A. (2004). Issues in CALL Evaluation. CALL 2004 Proceedings: CALL and Research Methodologies. University of Antwerp, Belgium. 179-189.

[21] Katagiri, K. (2012). Longitudinal measurements and developmental patterns of receptive vocabulary size: A study of Japanese university EFL students. JLTA Journal, Vol. 15, pp. 43-57.

[22] Laurillard, D. (2002). Rethinking University Teaching. A conversational framework for the effective use of learning technologies. London:

Routledge. [See Eduwiki (4/15/01) http://edutechwiki.unige.ch/en/Laurillard conversation al framework].

[23 ]Loucky, J. P. (2005). Developing and testing vocabulary training methods and materials for Japanese college students studying English as a foreign language. Ed. D. Dissertation Pensacola Christian College, Pensacola, FL. ERIC Center for Applied Linguistics via fax to (202) 429- 9292; or http://www.eric.ed.gov/ERICWebPortal/Home.portal? nfpb =true\&ERICExtSearch_SearchValue_0=JOHN+PAUL+lou cky+japanese\&searchtype $=$ keyword\&ERICExtSearch_Sear chType $0=k w \&$ pageLabel $=$ RecordDetails\&objectId $=0900$ 000b8013f95d\&accno=ED406844\&_nfls=false].

[24] Loucky, J. P. (2005). Combining beneficial strategies from both intensive and extensive reading approaches for more effective and enjoyable language learning. JALT 2004 Language Learning for Life: JALT 2004 Proceedings. K. Bradford-Watts, C. Ikeuchi, \& M. Swanson (Eds.), on JALT 2004 Conference Proceedings CD. Tokyo: JALT. Pages 1041-1055. [Retrieved from http://jalt-
publications.org/archive/proceedings/2004/E08.pdf

Loucky, J. P. (2006). Maximizing vocabulary development by systematically using a depth of lexical processing taxonomy, CALL resources, and effective strategies. CALICO Journal, 23, No. 2 (January), 363 $399 . \quad$ [Retrieved from https://calico.org/html/article_124.pdf].

[25] Loucky, J. P. (2010). Comparing electronic dictionary functions and use. CALICO Journal, 28(1), 156-174. [Accessed from http://journals.sfu.ca/CALICO/index.php/calico/article /view/885].

[26] Loucky, J. P., \& Tuzi, F. L. (2010). Comparing foreign language learners' use of online glossing programs. IJVPLE 1(4). IGI. [ igiglobal.com/Bookstore/TitleDetails.aspx?TitleId=1134].

[27] Qing Ma, \& Kelly P. (2006). CALL, Vol. 19, No $1,15-45$.

[28] Qing Ma. (2009). Second Language Vocabulary Acquisition. Bern: Peter Lang.

[29] Yamamoto, H. (1985). College students' retention of vocabulary learned during the three years of senior high school. Seinan Women's Junior College Bulletin, No. 32: 67-92. 